Frances Chung MD FRCP(C) John Miles MD FRCs(c)

\title{
Cardiac arrest following protamine administration
}

\begin{abstract}
A case report of fatal cardiac a rrest following protamine reversal of systemic heparinization during vascular surgery is presented. Patients who have received protamine zinc insulin, NPH insulin, and those with previous exposure to protamine sulphate or allergy to fish are more likely to have a reaction to protamine. Protamineinduced hypotension can be mediated by immunological or non-immunological mechanisms. Several alternative methads of heparin reversal which may avoid similar catastrophes are presented.
\end{abstract}

\section{Key words}

ANAPHYLAXIS: protamine; SURGERY: cardiovascular, peripheral vascular.

Protamine sulphate, a strong polycationic polypeptide, combines with acidic heparin to form a neutral salt, thus eliminating the anticoagulating properties of heparin. It is widely used in cardiac and vascular surgical procedures, and in donations of blood components when a cell separator is used. Severe anaphylactic reactions to protamine have been reported rarely. We recently observed a case of fatal hypotension following slow intravenous administration of $60 \mathrm{mg}$ of protamine in a diabetic patient receiving isophane insulin who had had prior exposure to protamine during vascular surgery.

\section{Case report}

A sixty-one-year-old male presented with a fourweek history of dysphasia, clumsiness, and pares-

From the Department of Anaesthesia and Surgery, University of Toronto and Toronto Western Hospital.

Address correspondence to: Dr. F. Chung, Department of Anaesthesia, University of Toronto, Toronto Western Hospital, 399 Bathurst Street, Toronto, Ontaria, M5T 2S8. thesias of right upper and lower extremities. He also had severe intermittent claudication and rest pain in his right lower leg for six months and a history of hypertension and diabetes for 30 years. Left femoro-popliteal bypass had been done six months prior to this admission. His medications were metoprolol $50 \mathrm{mg}$ b.i.d., NPH insulin 24 u q.a.m., 15 u q.p.m. and Toronto insulin 12 u q a.m. He had no history of allergy.

His weight was $60 \mathrm{~kg}$ and physical examination was unremarkable except for bilateral carotid bruit, and absent or reduced peripheral arterial pulses. His blood pressure on the ward was labile, ranging from $100 / 70$ to $200 / 100 \mathrm{mmHg}$. Laboratory investigations were normal, except for ST depression in ECG leads II, IIl, AVF, $V_{4}-V_{6}$. Angiography revealed 90 per cent stenosis of the left internal carotid artery, and 60 per cent stenosis of the right internal carotid artery and occlusion of the right superficial femoral artery

He was scheduled for left carotid endarterectomy. Prcmodication was $10 \mathrm{mg}$ valium, orally. Blood pressure was monitored with an arterial line. He was induced with fentanyl $200 \mu \mathrm{g}$, lidocaine $100 \mathrm{mg}$, thiopentone $150 \mathrm{mg}$, and pancuronium $5 \mathrm{mg}$, intravenously. Maintenance of anaesthesia was with oxygen, nitrous oxide and \pm 0.5 per cent enflurane. The blood pressure was stable at about $150 \mathrm{mmHg}$ systolic throughout the procedure. Heparin 6000 units was given, followed 25 minutes later by intravenous protamine $50 \mathrm{mg}$, after the endarterectomy. The blood pressure immediately fell to $80-90 \mathrm{mmHg}$, and a neosynephrine drip was required for one to two minutes to increase the blood pressure. The patient recovered uneventfully.

Seven days later the patient was scheduled for right femoro-popliteal bypass and right lumbar sympathectomy. A preoperative electrocardiogram showed no new findings. He received a spinal anaesthetic. Tetracaine $14 \mathrm{mg}$ was given at $\mathbf{L}_{3-4}$, which produced loss of sensation to the T8 level. He 
TABLE I Protamine reactions

\begin{tabular}{|c|c|c|c|c|c|}
\hline Author & SexiAge & Surgery & Pulmonary changes & Skin thonger & Cardine arrest \\
\hline Jackson $^{4}$ & $F / 63$ & Ilcofemoral endarterectomy & - & - & Yes, resuscitated \\
\hline Lakin ${ }^{3}$ & $\mathrm{M} / 29$ & Blood component donation & Dyspnosa, wheezing & Unticaria & - \\
\hline Moorthy ${ }^{6}$ & $F / 26$ & Nephrolithotomy & - & Skin flush & - \\
\hline Krape $^{7}$ & M/55 & Aorto coronary bypass & Bronchospasm & - & - \\
\hline \multirow[t]{3}{*}{ Doolan $^{8}$} & $\mathrm{M}$ & Cardiac catheterization & Apnoea & $\ldots$ & Yes, resuscituted \\
\hline & M & Carolid endarterectomy & Bronchospasm & - & Yes, resuscitated \\
\hline & M & Cardiac catheterization & Facial aedema stridor & - & Yes, resuscitated \\
\hline $\mathrm{Cobb}^{9}$ & $M / 51$ & Carotid endarterectomy & - & Skin flush & - \\
\hline$V_{\text {ont }}{ }^{10}$ & $M / 52$ & Carotid endarterecromy & Bronchospasm & Angioncurotic oedema & Neurological defici \\
\hline Nordstrom $^{19}$ & Fin 7 & Open heart surgery & Bronchospasm & - & - \\
\hline
\end{tabular}

*All cases included severe and prolonged hypotension.

was awake and conversed with the surgeon intermittently throughout the procedure. Right lumbar sympathectomy was done first. He then received 6000 units of heparin, and right femoro-popliteal bypass was done. Following release of the clamps good flow was noted in the graft, and the systemic blood pressure was $160 \mathrm{mmHg}$. At this time estimated blood loss was about $200 \mathrm{ml}$, and the fluids administered were $1000 \mathrm{ml}$ of plasmalyte solution, one unit of packed cells, and $100 \mathrm{cc}$ dextroseinsulin solution with 20 units of insulin in $1000 \mathrm{ml}$ of five per cent dextrose solution. Protamine $60 \mathrm{mg}$ was injected over one to two minutes and shortly thereafter the patient complained of difficulty breathing. Systolic blood pressure dropped precipitously to $40 \mathrm{mmHg}$. Despite prompt injections of neosynephrine, $0.5 \mathrm{mg}$ twice, $1 \mathrm{mg}$ adrenaline twice and intubation and ventilation with oxygen, the patient remained severely hypotensive. Peak airway pressure was $30 \mathrm{mmHg}$. The electrocardiogram still showed sinus rhythm at $60 / \mathrm{min}$ with no new ST-T wave changes. Despite cardiac massage, severe hypotension persisted and he developed ventricular fibrillation. He was defibrillated, and the clcctrocardiogram now showed marked ST elevation in the modified $V_{5}$ lead. A central line was inserted into the femoral vein and an arterial line was inserted into the femoral artery. Isoproterenol and dopamine drops were started. However, the patient again developed ventricular fibrillation and could not be resuscitated despite major efforts.

\section{Discussion}

Clinically, protamine is widely used without major complication. Recently, Milne observed that intra- venous protamine produced no significant change in blood pressure, heart rate, left atrial pressure, central venous pressure, systemic vascular resistance or cardiac index. ' However, hypotension can occur in some patients and there appear to be two types of reactions after protamine administration in humans. The first, seen in many patients, is a mild to moderate fall in blood pressure. This is due to a vasodilation effect of protamine as well as the possibility of depressed myocardial contractility. ${ }^{2,3}$

The second type of reaction is severe. Most of the case reports had clinical features suggestive of a type I anaphylactic response to protamine. ${ }^{4-10}$ In certain patients, IgE or IgG reaginic antibodies are produced in response to protamine. The IgE antibodies are attached to mast cells. The second exposure to protamine results in a combination of the antigen with $\mathrm{IgE}$ or $\mathrm{IgG}$ complexes which trigger the degranulation of mast cells, releasing histamine and other vasoactive amines. Most of the cases reported either note previous exposure to protamine, diabetics on protamine zinc insulin, or isophanc insulin, or allcrgy to fish.

Protamine is produced from sperm or mature testes of salmon, or related species belonging to the family salmonidae or clupeidae. Caplan and Berman described four patients who experienced an allergic reaction to protamine." Two of these patients were allergic to fish. Knape reported a patient who was allergic to fish and developed a severe anaphylactic reaction after receiving protamine. $^{\top}$

In infertile or vasectomized men, sperm was absorbed into the circulation. Protamine in the sperm acts as a chronic antigenic stimulus, and 
TABLE II Protamine reaction

\begin{tabular}{|c|c|c|c|c|c|}
\hline Author & Protamine dosage & Onset & Prior protamine exposure & Allergy io fish & Test \\
\hline Jackson $^{4}$ & $40 \mathrm{mg}$ over $1-3 r$ & Immediate & Exposed to protamine 4 years ago & - & - \\
\hline Lakin $^{5}$ & $6.5 \mathrm{mg}$ over $30 \mathrm{sec}$. & $\frac{1}{2}$ minute & Exposure to protamine 5 months ago & - & $\operatorname{Lg} \mathrm{G}^{\uparrow}$ \\
\hline Moothy ${ }^{6}$ & 20 mg over 5 minutes & 1 misute & Protamine zine insulin for 5 years & - & IgE $\uparrow$ \\
\hline $\mathrm{Knape}^{\mathrm{\gamma}}$ & $50 \mathrm{mg}$ & minute & - & Yes & $\operatorname{tgF} 1$ \\
\hline \multirow[t]{3}{*}{ Doolan" } & $35 \mathrm{mg}$ & Immediate & Reaction on the dth exposure & - & Positive skin test \\
\hline & $15 \mathrm{mg}$ & Immediate & Exposure to protamine 6 weeks ago & - & Positive skin test \\
\hline & $10 \mathrm{mg}$ & Immediate & NPH Insulin & - & Positive skin test \\
\hline Cobb $^{9}$ & $25 \mathrm{mg}$ over $1-2^{\prime}$ & Immediate & NPH lnsulin & - & - \\
\hline Vontz ${ }^{10}$ & $10 \mathrm{mg}$ & Immediate & NPH Insulin & - & $\left.\operatorname{IgE}\right|^{\dagger}$ \\
\hline Nordstrom ${ }^{14}$ & $60 \mathrm{mg}$ IV slowly & 1 minute & - & - & - \\
\hline
\end{tabular}

auto-antibodies to sperm occur. These patients may therefore be at increased risk to allergic reactions to protamine. ${ }^{12,13}$

The repeated administration of intravenous protamine could result in an anaphylactic reaction. Doolan reported a patient who had a severe reaction on his fourth exposure to protamine within two years. ${ }^{8}$ In a retrospective study of blood component donors, Lakin found that prior exposure to protamine is associated with an increased risk of adverse reaction. ${ }^{5}$ Of twenty-two initial protamine injections, no adverse reactions were observed. Of eleven donors receiving protamine a second time, four urticarial episodes with or without bronchospasm or hypotension were noted. There is evidence that the immunologic anaphylactic reaction is mediated by a complement dependent IgG skin sensitizing antibody.

In diabetic patients treated with protamine zinc insulin or NPH insulin, four case reports of anaphylactic reactions to protamine have been reported. ${ }^{6,8,10}$ The reactions were usually severe, with hypotension being prolonged in spite of vigorous treatment. Grant studied four diabetics on NPH insulin who had anaphylactic reactions to protamine during open heart surgery, and their findings were compatible with an immunological basis. Sensitization was probably induced by prior chronic exposure to protamine in NPH insulin or protamine zinc insulin.

Our patient had previously received $60 \mathrm{mg}$ protamine intravenously during left femoro-popliteal bypass, with no change in blood pressure. Six months later, he developed some degree of hypotension (which lasted for 1-2 minutes) following protamine injection. The blood pressure was easily elevated with a neosynephrine drip. Seven days later, following intravenous protamine he developed severe hypotension resistant to treatment and subsequently suffered massive myocardial infarction and cardiac arrest. It is possible that prior exposure to protamine with the previous vascular surgery and the protamine content of isophane insulin (NPH insulin 0.3-0.6 mg of protamine per 100 units of insulin) sensitized our patient to protamine. The interval between exposure is said to be important, with a short incubation period of two weeks being most optimal for devclopment and expression of drug allergy. ${ }^{16}$ The interval in our case was seven days.

The manifestation of this allergic reaction may have been accentuated by the co-existence of a peripheral sympathetic block due to the spinal anaesthesia. The spinal anaesthetic might have impaired the endogenous release of epinephrine from the adrenal glands; ${ }^{17}$ epinephrine normally acts to increase intracellular concentrations of cyclic adenosine monophosphate and thus inhibit degranulation of mast cells and reduce the release of chemical mediators. Furthermore, peripheral sympathetic block would prevent compensatory vasoconstriction during an allergic reaction and thus exaggerate the magnitude of hypotension. ${ }^{\text {is }}$

Only one case of non-immune anaphylactoid response has been reported. Nordstrom observed an anaphylactoid response in a six-year-old girl who had no prior exposure to protamine. She developed hypotension and bronchospasm after protamine chloride, which was treated with intravenous isoproterenol. ${ }^{19}$ Protamine, being a polycationic polypeptide, releases histamine from mast cells, and basophils. ${ }^{20}$ Complement consumption can be 
mediated by protamine ${ }^{21}$ or protamine-heparin complexes, ${ }^{22}$ and this may produce anaphylactoid symptoms. Rent found in vitro complement consumption to be most pronounced when protamine is in "excess" of heparin.

Increased protamine sensitivity should be kept in mind in patients who are receiving protamine zinc or isophane insulin, patients with previous exposure to protamine, or allergy to fish. During peripheral vascular surgery with small doses of heparin, the use of protamine should rarely be required. Spontancous reversal of anticoagulation is strongly encouraged. If protamine must be used, it is reconmended that $5-10 \mathrm{mg}$ as a small test dose be given, ${ }^{8}$ with intravenous adrenaline, vasopressors, and plasma volume expanding agents available. If a patient has a history of reaction to protamine, they should be appropriately premedicated with $50 \mathrm{mg}$ of prednisone orally every six hours for one day, and $50 \mathrm{mg}$ of intravenous diphenhydramine one hour before protamine. This regimen has been found to prevent severe reactions to contrast in patients with a past history of allergy to radiographic dye. ${ }^{23}$

As another approach in patients who have documented protamine allergy, hexadimethrine can be used as a safe alternative to protamine. " Hexadimethrine is not supplied by the pharmaceutical industry and must be prepared from a powder by the hospital pharmacy. The powder is available in Canada. Parsons has reported on eleven patients who were allergic to protamine. When hexadimethrine was used, there was 100 per cent success in reversal of heparin anti-coagulation without adverse reaction. *

Those patients who have developed a reaction to protamine should have intradermal skin testing, and their IgE and IgG antibodies and complement assessed. This should further elucidate the mechanism of the reaction.

In summary, we have attempted to draw attention to the possible precipitating factors, and the clinical clues to the existence of protamine sensitivity in a given patient. Avoidance of protamine reversal by natural degradation of heparin is often possible, but failing this, a small test dose of protamine with adrenaline on stand-by, or use of hexadimethrine may be lifesaving.

*Parsons, B. Personal communication. Austin Hospital, Heidelberg, Australia.

\section{Acknowledgments}

We wish to thank Mrs. I. Bell for her secretarial assistance.

\section{References}

1 Milne B, Rogers $K$, Cervenko $F$, Salerno $T$. The haemodynamic effects of intraaortic versus intravenous administration of protamine for reversal of heparin in man. Can Araesth Soc J 1983; 30: 34751.

2 Jastrzebski J, Sykes $M K$, Wood DG. Cardiorespiratory effects of protamine after cardiopulmonary bypass in man. Thorax 1974; 29: 534-8.

3 Shapira N, Schaff $H V$, Piehler $M$ et al. Cardiovascular effects of protamine sulphate in man. J Thorac Cardiovasc Surg 1982; 84: 505-14.

4 Jackson DR. Sustained hypotension secondary to protamine sulphate. Angiology 1970; 21: 295-8.

5 Lakin $I D$, Blocker TJ, Strong DM, Yocum MW. Anaphylaxis to protamine sulphate mediated by a complement-dependent IgG antibody. J Allergy Clin Immunol 1978; 61: 102-7.

6 Moorthy SS, Pond W, Rowland RG. Severe circulatory shock following protamine (an anaphylactic reaction). Anesth Analg 1980; 59: 77-8.

7 Krape JTA, Schuller JL, DeHann P, deJohr AP. Bovill $J G$. An anaphylactic reaction to protamine in a patient allergic to fish. Anesthesiology 1981; 55 : 324-5.

8 Doolan L, McKenzie I, Krafchek J, Parsons B, Buxton B. Protamine sulphate hypersensitivity. Anaesth Int Care 1981; 9: 147-9.

9 Cabb CA, Fung DL. Shock due to protamine hypersensitivity. Surg Neurol 1982; 17: 245-6.

10 Vontz FK, Puestow ED, Cahill DJ. Anaphylactic shock following protamine administration. Am Surg $1982 ; 48 ; 549-51$.

11 Caplan SN, Berman EM. Protamine sulphate and fish allergy. N Engl J Med 1976; 295: 172.

12 Hellema $H W J$, Rumke $P$. Sperm autoantibodies as a consequence of vascetomy. I. Within 1 year postoperation. Clin Exp Immunol 1978; 31: 18-29.

13 Samuel $T$. Antibodies reacting with salmon and human protamines in sera from infertile men and from vasectomized men and monkeys. Clin Exp Immunol 1977; 30: 181-7.

14 Grant JA, Cooper JR, Arens JF et al. Anaphylactic reactions to protamine in insulin dependent diabetics during cardiovascular surgery. Anesthesiology 1983; 59: (3A) A74. 
15 Koltai M, Blazso G, Ontecz A, Minker E. Some characteristics of the insulin-induced potentiation to anaphylactoid reaction in Sprague-Dawley rats. Acta Phy Aca Sci Hung, Tomus 1979; 54: 287-93.

16 Fox GS, Witkinson RD, Rabow FI. Thiopental anaphylaxis. A case and a method for diagnosis. Anesthesiology 1971; 35: 655-7.

17 Barnet $A S$, Hirshman $C A$. Anaphylactic reaction to cephapinin during spinal anaesthesia. Anesth Analg 1979; 58: 337-8

18 Hirshman CA, Peters J, Cartwright-Lee I. Leukocyte histamine release to thiopental. Anesthesiology 1982; 56: 64-7.

19 Nordstrom L, Fletcher $R$, Pavek K. Shock of ana phylactoid type induced by protamine - a continuous cardiorespiratory record. Acta Anaesthesiol Scand 1978; 22: 195-201.

20 Keller $R$. Interrelation between different types of cells. II. Histamine relcase from the mast cells of various species by cationic polypeptides of polymorphonuclear leukocyte lysosomes and other cationic compounds. Int Arch Allergy Appl Immunol 1968; 34: $139-44$.

21 Siegel K. Rent R, Gewurz H. Interactions of Creactive protein with the complement system. I. Protamine-induced consumption of complement in acute phase. Sera J Exp Med 1974; 140: 631-47.

22 Rent R, Ertel N. Eisenstein R, Gewurz H. Complement activation by interaction of polyanions and polycations. J Immunol 1975; 114: 120-4.

23 Kelly JF, Patterson R, Stevenson D, Mathison D. Radiographic contract media studies in high risk patients. J Allergy Clin Immunol 1978; 61: 146.

24 Weiss WA. Gilman JR, Catenacci AJ, Osterberg AE. Heparin neutralization with polybrene administered intravenously. JAMA 1958; 166: 603-7.

\section{Résumé}

On rapporte l' observation d' un arrêt cardiaque fatal à la suite d'administration de protamine durant un cas de chinurgie cardiovasculaire. Les malades qui reçoivent déjà de l'insuline-protamine-zinc on de l'insuline NPH, ceux qui ont reçu antérieurement du sulfate de protamine ef ceux allergiques au poisson sont pius susceptibles de présenter une réaction à la protamine. L'itypotension atribuable à l'administration de protamine peut s'ex. pliquer par un mécanisme immuntologique et un mécanisme non-immunologique. On discute de nombreuses autres mêthodes utilisables pour renverser l'effet de l' héparine chez des malades susceptibles de présenter de telles complications. 